\title{
A Concise and Flexible Synthesis of the Potent Anti-Influenza Agents Tamiflu and Tamiphosphor**
}

\author{
Jiun-Jie Shie, Jim-Min Fang, * and Chi-Huey Wong
}

Influenza remains a major health problem. The worldwide occurrences of avian flu have increased public awareness of the potential for global influenza pandemics. Tamiflu (oseltamivir phosphate, $\mathbf{1} \cdot \mathrm{H}_{3} \mathrm{PO}_{4}$; Scheme 1$),{ }^{[1]}$ a popular drug for

$$
\begin{gathered}
\text { organometallic } \\
\text { coupling } \\
\text { reactions } \\
2 \text { (oseltamivir carboxylic acid) } \\
\mathrm{A}=\mathrm{CO}_{2} \mathrm{H}, \mathrm{B}=\mathrm{NH}_{2} \\
\mathrm{~A}=\mathrm{PO}(\mathrm{ONH})_{2}, \mathrm{~B}=\mathrm{NH}_{2}
\end{gathered}
$$

effective inhibitor $\left(K_{\mathrm{i}}=19 \mathrm{~nm}\right)$ of the H274Y mutant of H5N1 neuraminidase. ${ }^{[3]}$ Furthermore, our preliminary study indicates that tamiphosphor is also orally bioavailable and protects mice against lethal influenza viruses. By comparison of the survival rate and mean survival time of infected mice (data not shown), tamiphosphor is found to be more effective than tamiflu against the H1N1 human influenza virus and at least equally effective against the recombinant $\mathrm{H} 5 \mathrm{~N} 1$ (NIBRG14) virus.

The current industrial synthesis of tamiflu relies on naturally occurring shikimic acid as a starting material. ${ }^{[4]}$ However, the availability of consistently pure shikimic acid may be problematic. One of the drawbacks of this large-scale synthesis lies in the manipulation of the potentially explosive azide reagent and intermediates. Several new synthetic methods for the preparation of tamiflu have been developed without using shikimic acid. ${ }^{[5]}$ To establish the cyclohexenecarboxylate core structure of tamiflu, various types of DielsAlder reactions have been applied. For example, Karpf and co-workers $^{[5, \mathrm{~s}]}$ have carried out the Diels-Alder reaction between an appropriately functionalized furan and acrylate, followed by enzymatic resolution, to obtain the chiral intermediate for the synthesis of tamiflu. In one approach by Shibasaki and co-workers, ${ }^{[6 a]}$ the Diels-Alder reaction of 1trimethylsilyloxy-1,3-butadiene with fumaryl chloride was utilized to construct the core structure; however, separation of the racemic mixture of a key intermediate (by HPLC on a chiral stationary phase) was required. Alternatively, the catalytic enantioselective Diels-Alder reactions developed by the research groups of Corey ${ }^{[7]}$ and Fukuyama ${ }^{[8]}$ afforded the required chiral cyclohexenecarboxylates for the synthesis of tamiflu. In another approach by the research group of Shibasaki, ${ }^{[6 \mathrm{~b}-\mathrm{d}]}$ a meso-aziridine derivative of 1,4-cyclohexadiene was prepared and subjected to a catalytic asymmetric ring-opening reaction with trimethylsilyl azide, which served as the platform methodology for the synthesis of tamiflu. Karpf and co-workers used $\mathrm{Ru} / \mathrm{Al}_{2} \mathrm{O}_{3}$-catalyzed hydrogenation of a substituted isophthalic diester to provide the cyclohexane core where all the substituents and the diester are disposed cis to one another. ${ }^{[5, \mathrm{a}, \mathrm{b}}$ The meso diester was then enzymatically hydrolyzed to an optically active monoacid, which serves as the key intermediate for the synthesis of tamiflu. Kann and co-workers ${ }^{[9]}$ demonstrated the synthesis of tamiflu by starting with the amination of a chiral cationic iron complex of cyclohexadienecarboxylate, which was obtained by separation of the diastereomers formed with $(1 R, 2 S)$-2-phenylcyclohexanol. Trost and Zhang reported a palladium-catalyzed asymmetric allylic amination of 5-oxabicyclo[3.2.1] hexen-4-one as a key step in the synthesis of tamiflu. ${ }^{[10]}$
Department of Chemistry

National Taiwan University, Taipei 106 (Taiwan)

Fax: $(+886)$ 2-2363-7812

Dr. J.-J. Shie, Prof. J.-M. Fang, Prof. C.-H. Wong

The Genomics Research Center

Academia Sinica, Taipei, 11529 (Taiwan)

[***] We thank the National Science Council for financial support, and the Advanced Instrumentation Center of the National Taiwan University for X-ray diffraction analysis.

9 Supporting information for this article is available on the WWW under http://dx.doi.org/10.1002/anie.200801959. 
We have reported the synthesis of tamiflu and tamiphosphor using Dxylose as an inexpensive starting material. ${ }^{[3]}$ The cyclohexene core of the target compounds is constructed by an intramolecular Horner-WadsworthEmmons reaction. ${ }^{[11]}$ Even though this flexible synthetic method provides both tamiflu and tamiphosphor in reasonable overall yields $\quad(5-13 \%)$, the lengthy reaction pathway (18 or 19 steps) is not ideal for a large-scale synthesis. Herein, we explore a more concise and practical synthetic route to tamiflu $\left(\mathbf{1} \cdot \mathrm{H}_{3} \mathrm{PO}_{4}\right)$ and tamiphosphor (3; Scheme 1). The enantiopure starting material used in our procedure, bromoarene cis-1,2-dihydrodiol (5), is commercially available and is easily produced on large scales by microbial oxidation of bromobenzene. ${ }^{[12]}$ As a result of their unique combinations of functionality, the haloarene cis-dihydrodiols have been successfully applied to the synthesis of various natural products and related molecules. ${ }^{[12]}$ In addition, the bromine atom can be transformed into various functional groups, including carboxylate and phosphonate, at a late stage of the synthetic sequence. Thus, the proposed synthetic strategy is versatile in that the common intermediates, for example $\mathbf{1 2}$ and $\mathbf{1 5}$, are of pivotal importance to prepare tamiflu, tamiphosphor, and other derivatives. Such late-stage functionalization is particularly appealing from a medicinal chemistry point of view.

Based on this synthetic plan, the acetonide of $\mathbf{5}$ was subjected to a $\mathrm{SnBr}_{4}$-catalyzed bromoacetamidation reaction with $\mathrm{N}$-bromoacetamide (NBA) in $\mathrm{CH}_{3} \mathrm{CN}$ at $0{ }^{\circ} \mathrm{C}^{[13]}$ to give bromoamide 6 in a regio- and stereoselective manner (Scheme 2). The structure of $\mathbf{6}$ was confirmed by X-ray diffraction analysis (see the Supporting Information). The reaction most likely proceeds by formation of a bromonium ion on the less hindered face, followed by a selective backside attack of the acetamide moiety at the allylic C5-position. In the presence of LHMDS (1.1 equiv), bromoamide $\mathbf{6}$ was converted into aziridine 7 , which underwent a $\mathrm{BF}_{3}$-mediated ring-opening reaction with 3-pentanol to give compound $\mathbf{8}$ in $73 \%$ yield. After removal of the protecting group, the cis-diol 9 was treated with $\alpha$-acetoxyisobutyryl bromide to afford the corresponding trans-2-bromocyclohexyl acetate 10. By analogy to precedented examples, ${ }^{[14]}$ this reaction might involve formation of an intermediate acetoxonium ion and a backside attack by a bromide ion at the allylic C2-position. The reaction of $\mathbf{1 0}$ with $\mathrm{LiBHEt}_{3}$ (super-hydride; 3 equiv) cleanly afforded $\mathbf{1 1}$ in $82 \%$ yield (from $\mathbf{9}$ ) by simultaneous reduction of the acetyl group and the bromine atom at the $\mathrm{C} 1$ - and $\mathrm{C} 2$ positions, respectively. The hydroxy group of $\mathbf{1 1}$ was successfully substituted by an azido group with inversion of configuration upon treatment with diphenylphosphoryl azide (DPPA) according to the Mitsunobu method to give $\mathbf{1 2}$ in $84 \%$ yield. $^{[3]}$ A small amount $(2 \%)$ of diene 13 , which is the side product generated by elimination of a water molecule, was also observed. The pivotal compound $\mathbf{1 2}$ was subjected to organometallic coupling reactions to incorporate the desired carboxyl or phosphonyl groups. Thus, the reaction of $\mathbf{1 2}$ with $\left[\mathrm{Ni}(\mathrm{CO})_{2}\left(\mathrm{PPh}_{3}\right)_{2}\right]$ in the presence of EtOH gave the ethyl ester $14 \mathbf{a}$ in $81 \%$ yield. ${ }^{[15]}$ On the other hand, phosphonylation of $\mathbf{1 2}$ with diethyl phosphite was achieved by using a catalytic amount of $\left[\mathrm{Pd}\left(\mathrm{PPh}_{3}\right)_{4}\right]$ to afford the phosphonate $\mathbf{1 4 b}$ in $83 \%$ yield. ${ }^{[16]}$ After reduction of the azido group of $\mathbf{1 4 a}$ and $\mathbf{1 4 b}$ to an amine moiety, tamiflu and tamiphosphor were 
respectively synthesized according to our previously reported procedures. ${ }^{[3]}$

The above synthetic method was further improved by the development of an azide-free process. ${ }^{[17]}$ We found that tetrabutylammonium cyanate was a good source for the amine functionality. Alcohol 11 was treated with $\mathrm{Bu}_{4} \mathrm{NOCN} /$ $\mathrm{PPh}_{3} / \mathrm{DDQ}$ to give an isocyanate intermediate ${ }^{[18]}$ which was subsequently treated with $t \mathrm{BuOH}$ to give carbamate $\mathbf{1 5}$ in $78 \%$ yield (Scheme 3 ). A Pd-catalyzed coupling reaction with

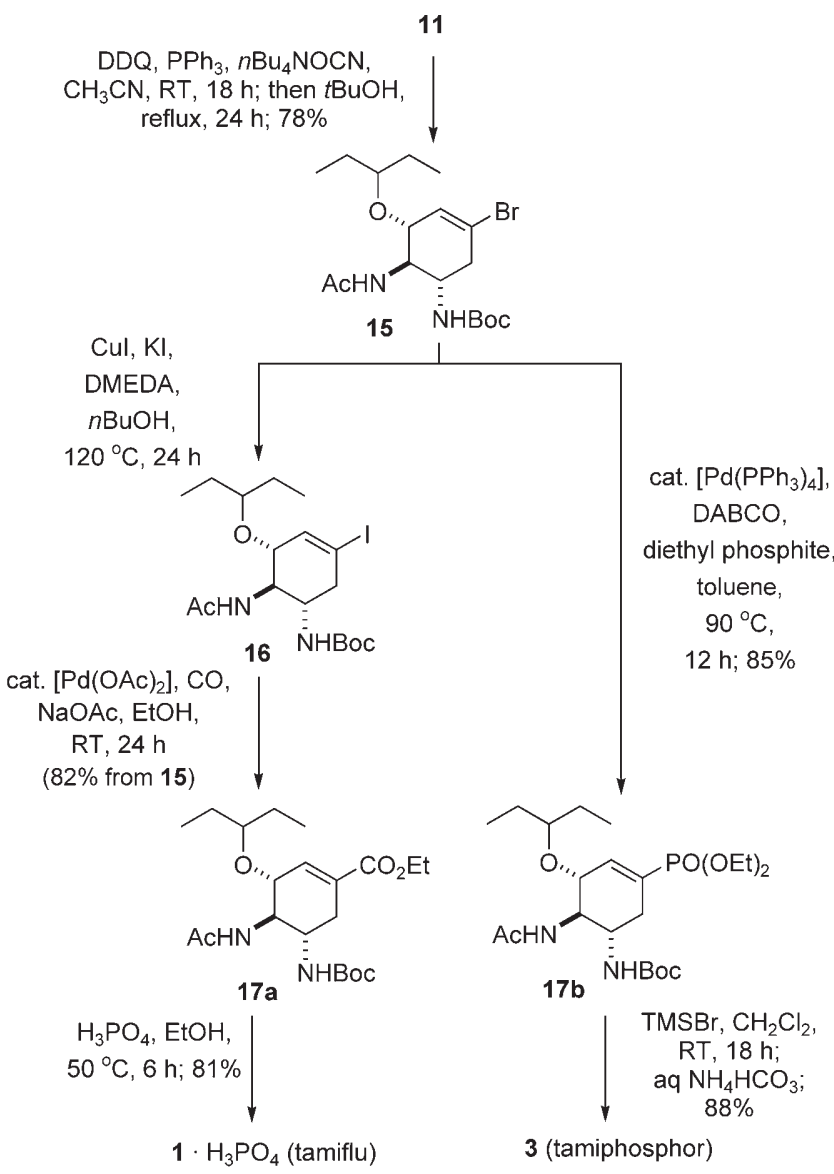

Scheme 3. Azide-free synthesis of 1. $\mathrm{H}_{3} \mathrm{PO}_{4}$ and 3. DDQ =2,3-dichloro5,6-dicyanobenzoquinone, DMEDA $=N, N^{\prime}$-dimethylethylenediamine, TMS = trimethylsilyl.

diethyl phosphite was carried out to form phosphonate $\mathbf{1 7} \mathbf{b}$, and subsequently tamiphosphor (3) was synthesized by concurrent removal of the Boc and the ethyl groups with TMSBr under mild reaction conditions. To avoid using a stoichiomeric amount of toxic $\left[\mathrm{Ni}(\mathrm{CO})_{2}\left(\mathrm{PPh}_{3}\right)_{2}\right]$, the Pdcatalyzed carbonylation of $\mathbf{1 5}$ was instead attempted, but was not successful. Alternatively, bromide $\mathbf{1 5}$ was converted into the more reactive iodide analogue $\mathbf{1 6},{ }^{[19]}$ and the Pd-catalyzed carbonylation was realized in a high yield to give carboxylate 17a. ${ }^{[20]}$ Finally, 17a was treated with $\mathrm{H}_{3} \mathrm{PO}_{4}$ to give tamiflu $\left(\mathbf{1} \cdot \mathrm{H}_{3} \mathrm{PO}_{4}\right)$; this was achieved through cleavage of the Boc group and formation of the phosphate salt in a one-pot operation.

In conclusion, tamiflu and tamiphosphor have been synthesized in $21-26 \%$ overall yields through an 11-step reaction sequence using the readily available starting material bromoarene cis-1,2-dihydrodiol (5), which can be supplied from the microbial oxidation of bromobenzene. All reactions were handled without using potentially hazardous intermediates or toxic reagents, and as most of the reactions occurred in a regio- and stereoselective fashion to give crystalline products throughout the synthesis $(6,9,11,12,14 \mathbf{a}, 15,17 \mathbf{a}$, $\mathbf{1 7} \mathbf{b}, \mathbf{1} \cdot \mathrm{H}_{3} \mathrm{PO}_{4}$, and $\mathbf{3}$ ), the isolation procedures were relatively simple and cost effective. Even though only a gram-scale synthesis is demonstrated in this study, the large-scale synthesis of tamiflu and tamiphosphor looks promising and will be useful for the development of anti-influenza drugs.

Received: April 25, 2008

Keywords: asymmetric synthesis - chiral pool · drug design . synthesis design $\cdot$ total synthesis

[1] a) C. U. Kim, W. Lew, M. A. Williams, H. Liu, L. Zhang, S. Swaminathan, N. Bischofberger, M. S. Chen, D. B. Mendel, C. Y. Tai, W. G. Laver, R. C. Stevens, J. Am. Chem. Soc. 1997, 119, 681-690; b) W. Lew, X. Chen, C. U. Kim, Curr. Med. Chem. 2000, 7, 663-672; c) K. McClellan, C. M. Perry, Drugs 2001, 61, $263-283$.

[2] a) Patient information sheet from the US Food and Drug Administration, March 10, 2008; b) I. Fuyuno, Nature 2007, 446, $358-359$.

[3] J.-J. Shie, J.-M. Fang, S.-Y. Wang, K.-C. Tsai, Y.-S. E. Cheng, A.S. Yang, S.-C. Hsiao, C.-Y. Su, C.-H. Wong, J. Am. Chem. Soc. 2007, 129, 11892-11893.

[4] a) C. U. Kim, W. Lew, M. A. Williams, H. Liu, L. Zhang, S. Swaminathan, N. Bischofberger, M. S. Chen, D. B. Mendel, C. Y. Tai, W. G. Laver, R. C. Stevens, J. Am. Chem. Soc. 1997, 119, 681-690; b) J. C. Rohloff, K. M. Kent, M. J. Postich, M. W. Becker, H. H. Chapman, D. E. Kelly, W. Lew, M. S. Louie, L. R. McGee, E. J. Prisbe, L. M. Schultze, R. H. Yu, L. Zhang, J. Org. Chem. 1998, 63, 4545-4550; c) M. Federspiel, R. Fischer, M. Hennig, H.-J. Mair, T. Oberhauser, G. Rimmler, T. Albiez, J. Bruhin, H. Estermann, C. Gandert, V. Göckel, S. Götzö, U. Hoffmann, G. Huber, G. Janatsch, S. Lauper, O. Röckel-Stäbler, R. Trussardi, A. G. Zwahlen, Org. Process Res. Dev. 1999, 3, $266-274$.

[5] For reviews of methods used in tamiflu synthesis, see: a) S. Abrecht, P. Harrington, H. Iding, M. Karpf, R. Trussardi, B. Wirz, U. Zutter, Chimia 2004, 58, 621-629; b) V. Farina, J. D. Brown, Angew. Chem. 2006, 118, 7488-7492; Angew. Chem. Int. Ed. 2006, 45, 7330-7334; c) S. Abrecht, M. C. Federspiel, H. Estermann, R. Fisher, M. Karpf, H.-J. Mair, T. Oberhauser, G. Rimmler, R. Trussardi, U. Zutter, Chimia 2007, 61, 93-99; d) M. Shibasaki, M. Kanai, Eur. J. Org. Chem. 2008, 1839-1850.

[6] a) K. Yamatsugu, S. Kamijo, Y. Suto, M. Kanai, M. Shibasaki, Tetrahedron Lett. 2007, 48, 1403 -1406; b) Y. Fukuta, T. Mita, N. Fukuda, M. Kanai, M. Shibasaki, J. Am. Chem. Soc. 2006, 128, 6312-6313; c) T. Mita, N. Fukuda, F. X. Roca, M. Kanai, M. Shibasaki, Org. Lett. 2007, 9, 259-262; d) M. Morita, T. Sone, K. Yamatsugu, Y. Sohtome, S. Matsunaga, M. Kanai, Y. Watanabe, M. Shibasaki, Bioorg. Med. Chem. Lett. 2008, 18, 600-602.

[7] Y.-Y. Yeung, S. Hong, E. J. Corey, J. Am. Chem. Soc. 2006, 128, $6310-6311$

[8] N. Satoh, T. Akiba, S. Yokoshima, T. Fukuyama, Angew. Chem. 2007, 119, 5836-5838; Angew. Chem. Int. Ed. 2007, 46, 57345736.

[9] K. M. Bromfield, H. Gradén, D. P. Hagberg, T. Olsson, N. Kann, Chem. Commun. 2007, 3183-3185. 
[10] B. M. Trost, T. Zhang, Angew. Chem. 2008, 120, 3819-3821; Angew. Chem. Int. Ed. 2008, 47, 3759-3761.

[11] a) G. W. J. Fleet, T. K. M. Shing, J. Chem. Soc. Chem. Commun. 1983, 849-850; b) G. W. J. Fleet, T. K. M. Shing, S. M. Warr, J. Chem. Soc. Perkin 1 1984, 905 -908; c) H. Streicher, J. Meisch, C. Bohner, Tetrahedron 2001, 57, 8851-8859; d) H. Streicher, C. Bohner, Tetrahedron 2002, 58, 7573-7581; e) B. K. Radatus, K. S. K. Murthy, G. Weeratunga, S. F. Horne, K. K. Kothakonda, E. C. G. Wolf, Z. Wang, US patent 20080009639 application, 2008.

[12] a) D. R. Boyd, G. N. Sheldrake, Nat. Prod. Rep. 1998, 15, 309324; b) T. Hudlicky, D. Gonzalez, D. T. Gibson, Aldrichimica Acta 1999, 32, 35-62; c) M. A. Endoma, V. P. Bui, J. Hansen, T. Hudlicky, Org. Process Res. Dev. 2002, 6, 525-532; d) M. G. Banwell, A. J. Edwards, G. J. Harfoot, K. A. Jolliffe, M. D. McLeod, K. J. McRae, S. G. Stewart, M. Vögtle, Pure Appl. Chem. 2003, 75, $223-229$; e) R. A. Johnson, Org. React. 2004, 63, $117-264$.

[13] Y.-Y. Yeung, X. Gao, E. J. Corey, J. Am. Chem. Soc. 2006, 128, $9644-9645$.
[14] a) S. Greenberg, J. G. Moffatt, J. Am. Chem. Soc. 1973, 95, 40164025; b) D. R. Boyd, N. D. Sharma, C. R. O'Dowd, F. Hempenstall, Chem. Commun. 2000, 2151-2152; c) D. R. Boyd, N. D. Sharma, N. M. Llamas, J. F. Malone, C. R. O'Dowd, C. C. R. Allen, Org. Biomol. Chem. 2005, 3, 1953-1963; d) D. R. Boyd, N. D. Sharma, N. M. Llamas, J. F. Malone, C. R. O'Dowd, C. C. R. Allen, Org. Biomol. Chem. 2006, 4, 2208-2217.

[15] A. J. Blacker, R. J. Booth, G. M. Davies, J. K. Sutherland, J. Chem. Soc. Perkin Trans. 1 1995, 2861-2870.

[16] B. Bessièrea, A. Schoenfelder, C. Verrat, A. Mann, P. Ornstein, C. Pedregal, Tetrahedron Lett. 2002, 43, 7659-7662.

[17] a) M. Karpf, R. Trusardi, J. Org. Chem. 2001, 66, 2044-2051; b) P. Harrington, J. D. Brown, T. Foderaro, R. C. Hughes, Org. Process Res. Dev. 2004, 8, 86-91.

[18] B. Akhlaghinia, Synthesis 2005, 1955-1958.

[19] J. L. Humphreys, D. J. Lowes, K. A. Wesson, R. C. Whitehead, Tetrahedron 2006, 62, 5099-5108.

[20] N. A. Bumagin, K. V. Nikitin, I. P. Beletskaya, J. Organomet. Chem. 1988, 358, 563-565. 